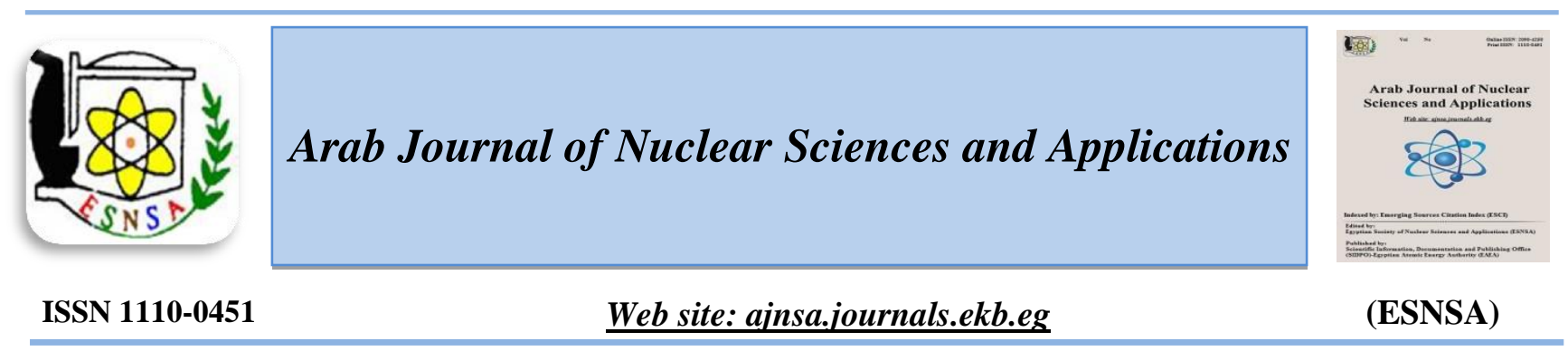

\title{
Improved Surface Properties of Copper/Polymethyl Methacrylate Nanocomposite Films Using DC O2 Plasma
}

\author{
Naglaa M. EL-Sayed, Omar F. Farag, Doaa A. Nasrallah \\ Physics Department Faculty of Science, Zagazig University, Zagazig, Egypt
}

Received $29^{\text {th }}$ Apr. 2019 Accepted $12^{\text {th }}$ Dec. 2019

\begin{abstract}
Films of Polymethylmethacrylate with copper nanofiller were prepared and treated with low temperature oxygen DC glow discharge plasma. FTIR spectroscopy, AFM, water contact angle (WCA) measurements and UV-Vis spectroscopy were used to detect the produced chemical, morphological and optical changes as a function of plasma treatment time. The FTIR spectra, showed a decreasing value of the main characterizing signals of the composite films in addition to the creation of an oxygen containing functional group. The surface morphology of the treated samples was altered according to the increased values of the average surface roughness, obtained from the AFM images. The WCA also, decreased noticeably with increasing treatment time. The UV-Vis spectroscopic analysis showed a decreasing value of the optical absorption in the wave length range 190-270 $\mathrm{nm}$ which is an indication to the loss of carbonyl group. The value of direct and indirect optical band gap decreased with treatment time meanwhile, values of the band tail width were significantly increased.
\end{abstract}

Keywords: $\mathrm{O}_{2}$ DC Plasma, Plasma surface modification, Cu/PMMA Nanocomposites films

\section{Introduction}

Research efforts in producing polymeric materials with unique properties have led to the incorporation of nano-particle materials into the polymeric matrices, which facilitates the exchange of properties between the phases and hence, widen their applications [1-6]. Tremendous efforts were made on mixing metal nanoparticles into a polymer matrix to generate new materials called metal nanocomposites [7]. These metal nanoparticles (NPs) have attracted much attention because of their wide range of applications in, optical fibers, waveguides, nonlinear optical switches, imaging materials, household appliances, automotive and various medical applications [8$15]$.

In this study $\mathrm{Cu} / \mathrm{PMMA}$ nanocomposite films were prepared and treated with low temperature DC glow discharge oxygen plasma for surface and chemical modification. PMMA is an important polymeric material having several excellent properties such as, low cost, good tensile strength, hardness, high rigidity, transparency, low optical, high light transmittance low glass temperature, high electrical resistivity and thermal stability. PMMA has the chemical structure, $[\mathrm{CH} 2 \mathrm{CH}$ $(\mathrm{CO} 2 \mathrm{H})]_{\mathrm{n}}$ and it is amorphous in nature. It is used in a wide variety of products including airplanes, cars, jewelry and electronic devices, in addition to a large number of medical devices which are made of PMMA such as, cement, contact lenses, blood filters, plastic surgery filler, and tooth filler. $\mathrm{Cu}$ NPs have many applications in industry, including its uses in gas sensors, batteries and super conductors. The most important feature characterizing $\mathrm{Cu}$ NPs is its antimicrobial activity against many infectious organisms [16, 17].

Nanocomposite materials generally, have excellent bulk physical and chemical properties. However, certain properties such as low surface adhesion,

Corresponding author: nagla68mohammed@gmail.com

DOI: 10.21608/ajnsa.2019.12400.1214

(C) Scientific Information, Documentation and Publishing Office (SIDPO)-EAEA 
low wettability and high electrical resistivity sometimes limit their applications. Different methods have been developed to overcome these problems and obtain the desired surface properties. Among these methods, is the use of nonequilibrium plasmas for surface modifications which is a rapidly growing research fields. Plasma, as a surface modification technique, has the ability to change the surface morphology, chemical structures without affecting the bulk properties of the treated material [18-21]. Plasma's active species and energetic photons generated by the discharge have major contributions to the modification of polymer surface. Four main effects can be induced on the treated surfaces, namely, surface cleaning, ablation, crosslinking and surface chemical functionalization [22]. The literature shows a considerable amount of experimental data regarding the effects of plasma on the surfaces of a large variety of materials. S. Kitova et al. [23] found that, the surface free energy of PMMA and $\mathrm{PC}$ increased after treatment with $\mathrm{Ar}, \mathrm{Ar} / \mathrm{H}_{2} \mathrm{O}$ and $\mathrm{Ar} / \mathrm{C}_{2} \mathrm{H}_{5} \mathrm{OH}$ soft plasma. Darain F.et al. [24] improved the surface wettability of PMMA substrates as a result of $\mathrm{O}_{2}$ plasma treatment. B.L.E. Sánchez et al. [25] enhanced the antibacterial properties, surface wettability and surface roughness of $\mathrm{PP} / \mathrm{Ag}$ and $\mathrm{PP} / \mathrm{Cu}$ nanocomposite by argon plasma treatment. F.O. Farag [26] studied the effect of DC $\mathrm{N}_{2}$ and $\mathrm{Ar}$ plasmas on the surface of PS films. The surface free energy and surface roughness of the treated samples were increased remarkably with increasing the plasma treatment time.

The $\mathrm{O}_{2}$ DC glow discharge treated films were characterized by the, FTIR spectroscopy, AFM, the water contact angle (WCA) measurements in addition to the UV-Vis absorption spectroscopy.

\section{Material and methods}

Sample preparation

$\mathrm{Cu} / \mathrm{PMMA}$ nanocomposite films, with a $\mathrm{Cu}$ contentof $1 \mathrm{w} . t \%$, were prepared by the solutioncasting method.PMMAin the form of grains and CuNPs, of particle size $60 \mathrm{~nm}$, obtained from Sigma-Aldrich Company. 2 gram of PMMA granules were dissolved in $40 \mathrm{~mL}$ of toluene (with purity 99.99).The mixture was vigorously stirred using a magnetic stirrer till a clear solution is formed. Then $0.02 \mathrm{gm}$ of $\mathrm{Cu}$ nanoparticles was added and stirring was continued till a homogenous suspended solution obtained. The solution was poured into a clean glass Petri dish, and the solvent was allowed to evaporate in a dry atmosphere, at room temperature, for several days. After complete dryness, the samples, with a thickness $\approx 0.25 \mathrm{~mm}$, were removed from Petri dish and cut into rectangular sheets $(1 \mathrm{~cm} \times 2 \mathrm{~cm})$.

\section{Plasma treatment}

$\mathrm{Cu} / \mathrm{PMMA}$ nanocomposite films were treated in a DC glow discharge reactor described in details in a previous work [27].The discharge parameters were kept unchanged through the whole experiment. The base pressure of the plasma reactor was $10^{-3}$ Torr, then it was increased to 0.4 Torr after feeding with oxygen gas and the input power was about 3.5 Watt. The sample is supported on a glass holder and located in the negative glow region of the discharge, about $2 \mathrm{~cm}$ apart from the cathode.

\section{Sample characterization}

Chemical modifications before and after plasma treatment were characterized by Fourier transform infrared spectroscopy (FTIR). The measurements were performed using Bruker Alpha spectrophotometer in the wave number range of $\left(400 \mathrm{~cm}^{-1}-4000 \mathrm{~cm}^{-1}\right)$ in the absorbance mode. Water contact angle (WCA) measurements were used to examine hydrophilicity modification of the nanocomposite films using a traveling microscope based on taking a high quality photo of the liquid drop. All contact angles are the mean value of four measurements on different locationson the same sample. Surface morphology and roughness analysis of $\mathrm{O}_{2}$ plasma-treated surfaces were conducted by means of atomic force microscopy (AFM) using a WET-SPM scanning probe microscope (Shimadzu, Japan). UV-Visible spectral analysis was also done to identify the effect of plasma treatment on optical properties of $\mathrm{Cu}$-PMMA nanocomposites films using a PerkinElmer Lambda 950 spectrophotometer over a wavelength range $200-900 \mathrm{~nm}$.

\section{Results and discussion \\ FTIR analysis}

The FTIR spectrum of untreated and $\mathrm{O}_{2}$ plasma treated samples was carried out to examine the chemical modification of the treated films. Figure (1-a) shows the major characteristic absorption bands belonging to the untreated $\mathrm{Cu} / \mathrm{PMMA}$ film. According to the literature [28-30], the peaks at 
$2948 \mathrm{~cm}^{-1}$ and $2992 \mathrm{~cm}^{-1}$ are attributed to $\mathrm{CH}_{3}$ and $\mathrm{CH}_{2}$ stretching respectively. The intense absorption peak at $1721 \mathrm{~cm}^{-1}$ is attributed to $\mathrm{C}=\mathrm{O}$ vibration in the pendant group $-\mathrm{COOCH}_{3}$ in the PMMA. The peaks at $1441 \mathrm{~cm}^{-1}$ and $1062 \mathrm{~cm}^{-1}$ are from $\mathrm{CH}_{2}$ bending vibration and $\mathrm{C}-\mathrm{O}$ bond stretching respectively. The band between 1385 and 748 are due to $\alpha-\mathrm{CH}_{3}$ vibrations. All the previous results are attributed to pure PMMA characteristics. However, $\mathrm{Cu}$ NPs didn't show any characterizing signals and this may be an indication that $\mathrm{Cu}$ NPs could be encapsulated in the PMMA polymer microspheres, and the PMMA layer would shield any characteristic signal due to copper oxidation or contamination $[31,32]$.

The FTIR spectra of the treated samples Figure (1b - e) have similar peaks to the untreated one, however their intensity showed a decreasing behavior with increasing the treatment time. The peaks between $2948 \mathrm{~cm}^{-1}$ and $2992 \mathrm{~cm}^{-1}$ have their highest intensities in the untreated sample, while getting weakened with increasing treatment time. This can be interpreted in terms of BougerLambert-Beer law, which states that the absorbance in infrared transmission spectra is directly proportional to the concentration of the absorbing functional group as: $\quad A=\varepsilon C h$; where $A$ is the absorbance, $\varepsilon$ is the extinction coefficient, $C$ the concentration and $h$ is the sample thickness [30]. This result suggests that the percentage of $-\mathrm{CH}_{3}$ terminal function groups on the surface of the untreated film is more than the treated one and similarly for the rest functional groups. The diminishing of carbonyl group $(\mathrm{C}=\mathrm{O})$, at $1721 \mathrm{~cm}^{-1}$, and the decrease in its intensity with increasing treatment time is an indication to the occurrence of surface crosslinking of the treated samples or due to surface etching by plasma [33].This result is in agreement with previously published work [24, 34, 35], who supported their result by EDX and XPS analysis which proved the reduction of $\mathrm{C}$-atoms percentage and increasing that of O-atoms. The FTIR monitored a new created broad peak extending from $3100 \mathrm{~cm}^{-1}$ to $3600 \mathrm{~cm}^{-1}$ for samples treated for 45 and $60 \mathrm{~min}$. and this range belongs to the hydroxyl $(-\mathrm{OH})$ group. It is well known that in $\mathrm{O}_{2}$ plasma, as an oxidative medium, the creation of hydroxyl group is mainly due to the chemical interaction between the active plasma species and the surface atoms [36].This is in addition to the adsorption of moisture from the residual water vapor, which commonly exist in low pressure plasma reactor, or from ambient air just after removing the samples from the plasma chamber.

\section{Surface morphology}

The detailed surface morphology of the untreated and treated samples can be seen in the AFM images Figs. (2 and 3) from which the changes induced due to plasma treatment can be examined. Figure (2) shows that, the untreated film appears to be almost flat however, upon plasma treatment many hell-like granules protruded out of the surfaces and their number increased with increasing treatment time.

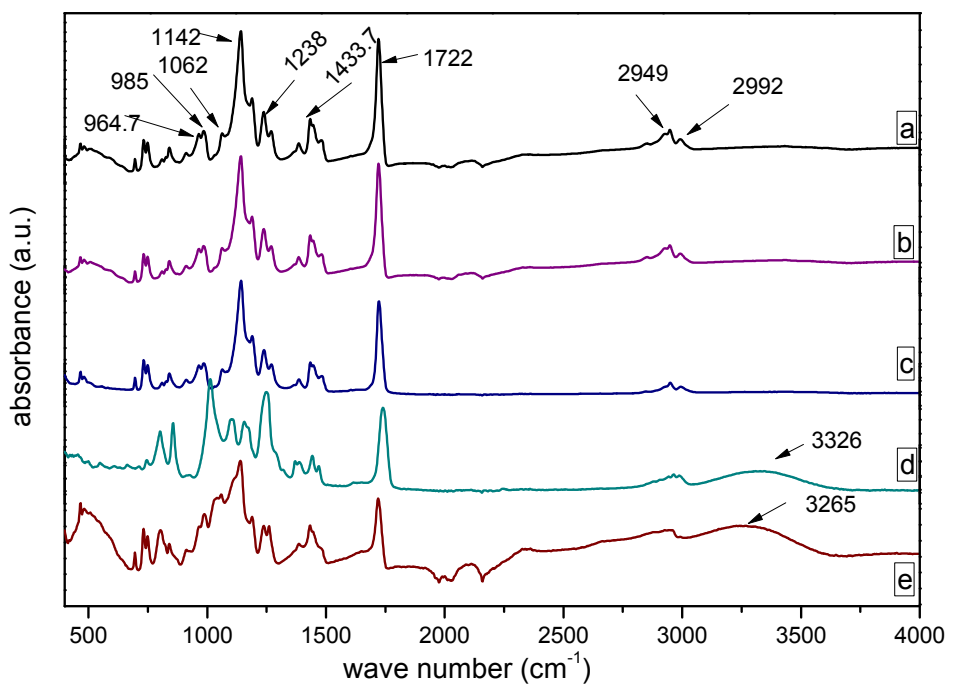

Figure (1): FTIR spectra of untreated [a] and treated films for $15 \mathrm{~min}$ [b], $30 \mathrm{~min}$ [c], 
45min. [d] and 60min. [e]

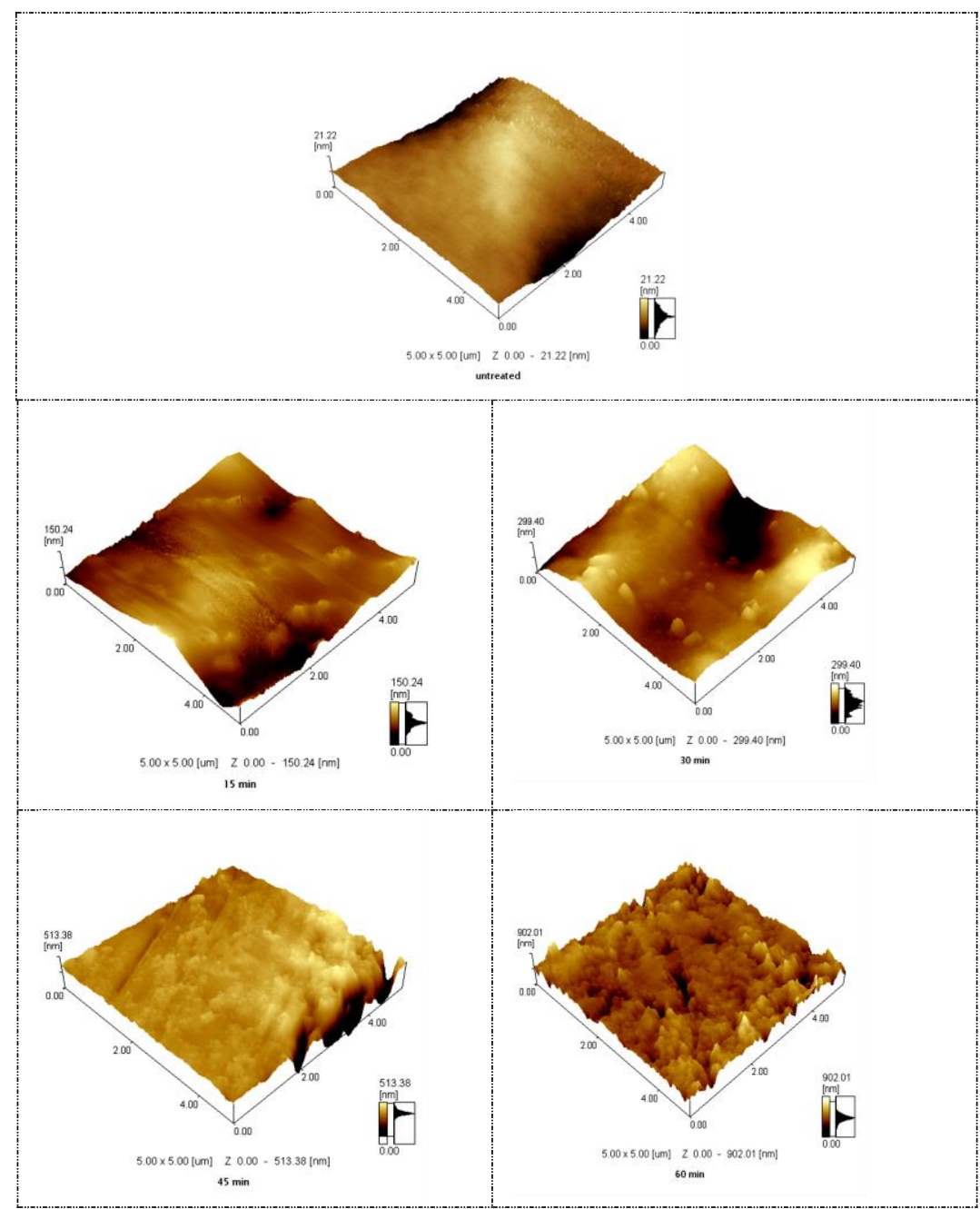

Figure (2): AFM images for untreated and plasma treated samples for different treatment time

This result was confirmed also, by the particle analysis given by the two-dimension AFM images shown in Figure (3). The average roughness increased from $0.8 \mathrm{~nm}$ For untreated sample to 1 $\mathrm{nm}$ for $15 \mathrm{~min}, 1.9 \mathrm{~nm}$ for $30 \mathrm{~min}, 1.5$ for $45 \mathrm{~min}$ and 1.6 for $60 \mathrm{~min}$. Increasing surface roughness with increasing treatment time can be referred to the etching effect due to the bombardment of the most energetic plasma species on the film's surface. It was reported that [37], extensive etching was observed upon treating a polymeric material with $\mathrm{O}_{2}$ plasma. Atomic oxygen reacts with the surface carbon atoms producing volatile reaction products removed from the surface through a reactive etching process which is also called aching.

Surface wettability
Many applications of polymer nanocomposites, especially in the field of biocompatibility, require the surfaces to be of high wettability. The wettability of the $\mathrm{Cu} / \mathrm{PMMA}$ films was examined by measuring the WCA for the samples treated with $\mathrm{O}_{2}$-plasma for different treatment durations. The results, given in Figure (4), shows that the value of WCA of the untreated sample agreed with reported values for pure PMMA [19, 38].This means that, the doped $\mathrm{Cu}$ NPs are covered with the polymer matrix so that it has no effect on the value of the contact angle of films. The contact angle showed a decreasing trend with increasing the treatment time. Its initial value was $78.67^{\circ}$ which dropped to $46.5^{\circ}$ after about $90 \mathrm{~min}$ of $\mathrm{O}_{2}$ plasma treatment. According to the literature $[39,40]$, the decreasing values of WCA can follow the exponential relation: 
$\theta=\theta_{\infty}+\left(\theta_{i}-\theta_{\infty}\right) e^{-k \tau}$



Figure (3): AFM particle analysis for untreated and plasma treated samples for different treatment time

It has been established that the hydrophilic

Where $\theta$ is the WCA at the corresponding treatment time $\tau, \theta_{\infty}$ is the WCA at maximum properties of plasma treated surfaces are mostly attributed to the changes in their chemical and

treatment time, $\theta_{i}$ is the initial WCA and $\kappa$ is the surface activation rate constant. According to our experimental data, $\kappa$ was found to have an average value of $0.03 \mathrm{~s}^{-1}$ which is a very small value compared to that reported in the literature [41]. The reason of this can be attributed to the prolonged time of treatment.

morphological properties. The FTIR spectra confirmed the chemical changes of the treated surfaces, and it detected the incorporation of $-\mathrm{OH}$ polar group on the surfaces of the samples treated for 45 and $60 \mathrm{~min}$. which in turn, increases the surface polarity and hence enhances its wettability. Increasing surface roughness with increasing treatment time, as showed in the AFMimages, is 
known to be associated with increasing the effective contact area of the surface.

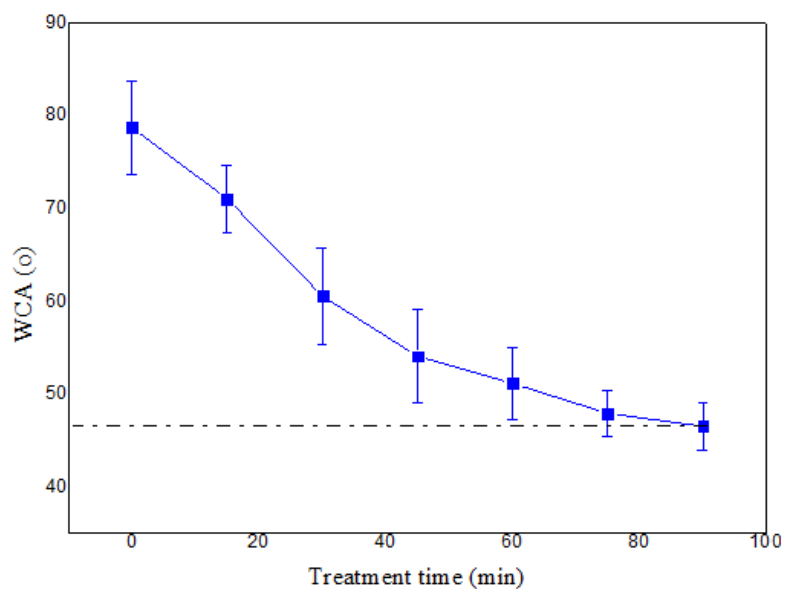

Figure (4): Water contact angle as a function of plasma treatment time

\section{UV-Vis analysis}

Figure (5) shows the UV-Vis absorption spectra of unirradiated and $\mathrm{O}_{2}$ plasma irradiated $\mathrm{Cu} / \mathrm{PMMA}$ nanocomposite films in the wavelength range of 200-900 nm. A remarkable decrease in the optical absorption with increasing treatment time for the irradiated samples can be observed in the wavelength range 190-270 $\mathrm{nm}$. This decrease could be attributed to the loss of carbonyl group $(\mathrm{C}$ $=\mathrm{O})$ due to the oxidative decomposition of the double bonds or plasma etching effect during irradiation with $\mathrm{O}_{2}$ plasma [42]. In the wavelength range $270-900 \mathrm{~nm}$, the optical absorption increases with increasing the irradiation time. Also, it can be noticed the existence of a shift in the absorption edge of the spectra toward the longer wavelength for plasma irradiated samples. This shift is an indication for the reduction in optical energy gap and could be attributed to the induced defects in the polymeric materials by the irradiation [43, 44].

The values of indirect and direct optical energy band gap were determined by plotting $(\alpha \mathrm{h} v)^{\mathbf{1} / 2}$ and $(\alpha h v)^{2}$ versus the photon energy (hv) according to Tauc's equation [45] from the extrapolation of the straight parts of the curves $\left[(\alpha h v)^{1 / 2}\right.$ and $(\alpha h v)^{2}$ versus (hv)] to the energy axis as showed in Figure (6). The band tail width (Urbach energy) values were obtained by using Urbach rule from the inverse of the slope $\ln (\alpha)$ versus the photon energy (hv) [46].

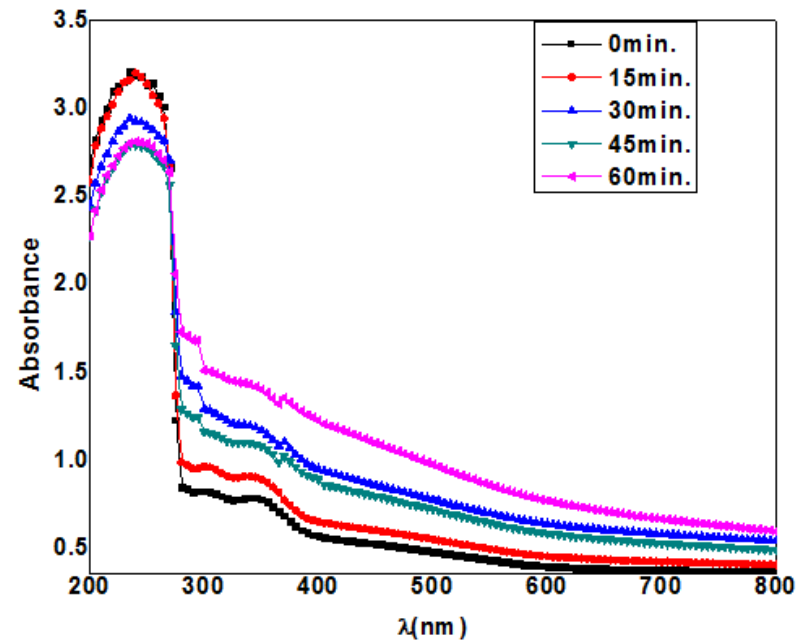

Figure (5): UV-viss absorption spectra of Cu/PMMA nanocomposite samples treated with $\mathrm{O}_{2}$ plasma for different irradiation times

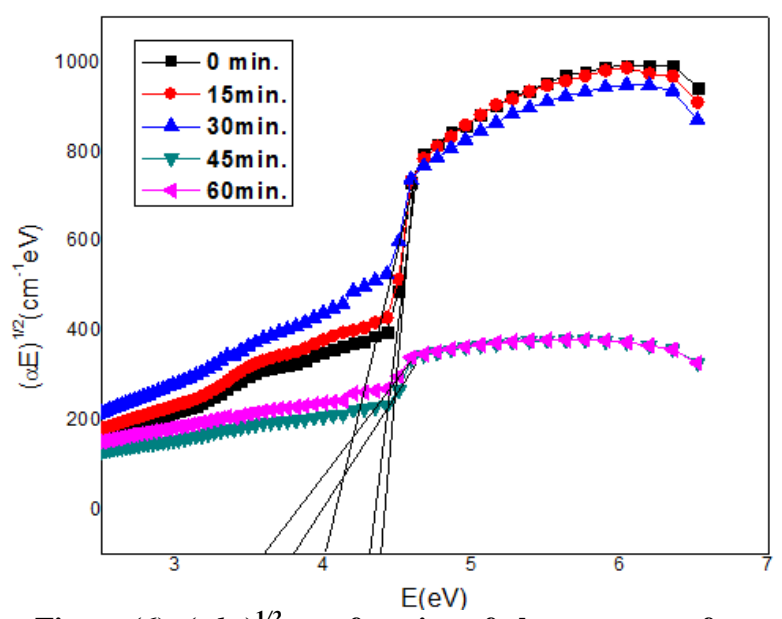

Figure (6): $(\alpha h v)^{1 / 2}$ as a function of photon energy for unirradiated and $\mathrm{O}_{2}$ plasma irradiated $\mathrm{Cu} / \mathrm{PMMA}$ nanocomposite films

The calculated values of the optical energy band gab; $E_{g}$, and band tail width (Urbach energy), $E_{u}$, for $\mathrm{Cu} / \mathrm{PMMA}$ films upon exposure to the $\mathrm{DC} \mathrm{O}_{2}$ plasma for different exposure time are tabulated in Table (1). It has been observed that both direct and indirect optical energy band gap decrease while Urbach energy increases with increase in the exposure time. It has been also observed that the values of indirect energy gap are lower than those for direct energy gap for the same exposure time. The decrease in optical energy band gap upon plasma exposure could be attributed to the scission process of polymer chain which results in unsaturation and creation of free radicals leading to increasing the conductivity of $\mathrm{Cu} / \mathrm{PMMA}$ composite samples [47]. The decreasing behavior of optical energy gap with the exposure time is 
similar to that reported by Farag, et al. [48]. On the other hand, the increasing of $E_{u}$ values with the plasma treatment may be attributed to the increase of the width of localized states which is an evidence for increasing the disorder in the treated $\mathrm{Cu} / \mathrm{PMMA}$ films [49].

Table (1): Optical energy band gap $\left(E_{g}\right)$ and band tail width $\left(E_{U}\right)$ of pristine and oxygen plasma irradiated Cu/PMMA nanocomposite films

\begin{tabular}{cccc}
\hline $\begin{array}{c}\text { Treatment } \\
\text { time } \\
\text { ( min.) }\end{array}$ & $\begin{array}{c}\text { In direct } \\
\mathbf{E}_{\mathbf{g}}\end{array}$ & $\begin{array}{c}\text { Direct } \\
\mathbf{E}_{\mathbf{g}}\end{array}$ & $\mathbf{E}_{\mathbf{u}}$ \\
\hline $\mathbf{0}$ & 4.43 & 4.5 & 0.183 \\
$\mathbf{1 5}$ & 4.22 & 4.40 & 0.211 \\
$\mathbf{3 0}$ & 4.12 & 4.41 & 0.361 \\
$\mathbf{4 5}$ & 3.8 & 4.35 & 0.317 \\
$\mathbf{6 0}$ & 3.58 & 4.30 & 0.526 \\
\hline
\end{tabular}

\section{Conclusion}

In this work, an investigation was carried out for the enhancement of surface hydrophilicity and optical properties of $\mathrm{Cu} / \mathrm{PMMA}$ nanocomposite films, due to low power oxygen DC plasma. The results showed that even with such low power treatment, the film's surfaces showed significant alterations. The FTIR spectra showed a decreasing in the value of the main characterizing signals of the composite films in addition to the creation of $\mathrm{OH}$ group, which leads to the increase of surface polarity. The surface morphology of the treated samples was altered according to the increased values of the average surface roughness, obtained from the AFM images. The WCA also, decreased noticeably with increasing treatment time. The UV-Vis spectroscopic analysis showed a decreasing value of the direct and indirect optical band gap in the main time values of the band tail width were significantly increased as a function of treatment time.

\section{References}

1-Sang, Y.Y., Sung, H. J. (2003) Preparation and characterization of polypropylene/silver nanocomposite fibers, Polymer international, 52(7), 1053-1057.

2-Dr. Kavitha, D., Sindhu, T. K., Nambiar, T. N. (2017) Impact of permittivity and concentration of filler nanoparticles on dielectric properties of polymer nanocomposite, IET Science, Measurement and Technology, 11, 179-185.

3-Olga, A. S., Vyacheslav, I. R., Andrey, A. A., Elena, S. S., Pavel, V. S., Zinaida, B. S. (2017) The effect of size and concentration of nanoparticles on the glass transition temperature of polymer nanocomposites, RSC Adv, 7, 50113-50120.

4-Christian, H., Dmitry, V. B., Brian, Y., Hermawan, K. D., Frank, C. W., (2019) Polymer nanocomposites having a high filler content: synthesis, structures, properties, and applications, Nanoscale, 11, 46534682.

5-Poblete, V.H., lvarez, M.P., Fuenzalida, V.M. (2009) Conductive Copper-PMMA Nanocomposites: Microstructure, Electrical Behavior, and Percolation Threshold as a Function of Metal Filler Concentration, Polymer Composites, 30, 328-333,.

6-Mosalman, S., Rashahmadi, S., Hasanzadeh, R. (2017) The Effect of $\mathrm{TiO} 2$ Nanoparticles on Mechanical Properties of Poly Methyl Methacrylate Nanocomposites, Transactions B: Applications, 30, 807-813.

7-Tamayo, L., Azócar, M., Kogan, M., Riveros, A., Paez, M. (2016) Copper-polymer nanocomposites: An excellent and cost-effective biocide for use on antibacterial surfaces, Materials Science and Engineering C ,69, 1391-1409.

8-Alsharaeh, E.H. (2016) PolystyrenePoly(methylmethacrylate) Silver Nanocomposites: Significant Modification of the Thermal and Electrical Properties by Microwave Irradiation, Materials, 9, 458-475.

9-Lee1, H., Park, S.H., Seo, S.G., Kim, S.J., Kim, S.C., Park, Y.K., Jung, S.C. (2014) Preparation and Characterization of Copper Nanoparticles via the Liquid Phase Plasma Method,Current Nanoscience, 10, 7-10.

10-Rosales, M.N., Orta, C.A., Velázquez, M.G., Ortiz, H.O., Hernández, E.H., Morones, P.G., Solís, S.G., Barrera, R.M., Sánchez, B.L. (2014) Effect of Plasma Polymerization of Copper Nanoparticles using Acrylic monomers on their antibacterial properties., Plasma Processes and Polymers, 11, 685-693.

11- Mahmoodi, S., Elmi, A., H.Nezhadi, S. (2018) Copper Nanoparticles as Antibacterial Agents, Journal of Molecular Pharmaceutics \& Organic Process Research, 6 (1), 140, 1-7.

12-Usman, M.S., El Zowalaty, M.E., Shameli, K., Zainuddin, N., Salama, M.,.Ibrahim, N.A (2013) Synthesis, Characterization and antimicrobial properties of copper nanoparticles, Int J Nanomedicine, 8, 4467-4479.

13-Agrawal, N. K., Agarwal, R., Vijayand Y. K., Swami, K. C. (2014) Surface Treatment of CoS/PolymerNanocomposite Membranes for Improving Wettability and Surface Energy, Journal of Materials Science \& Surface Engineering, 1 (3), 69-74.

14-Vijayakumari, G., Selvakumar, N., Jeyasubramanian, K., Mala, R. (2013) Investigation on the Electrical Properties of Polymer metal Nanocomposites for Physiological sensing applications, Physics Procedia, 49, 67 - 78. 
15- Chen, X., Lei, H., Xu, T., Zhang, J., Qiu, Y., Tan, L. (2017) Preparation of PMMA/Nano-Cu Antibacterial Plastic by In Situ Polymerization", Key Engineering Materials, 727, 815-818.

16-Tamilvanan, A., Balamurugan, K., Ponappa, K., Madhan, K. B. (2014) Copper Nanoparticles: Synthetic Strategies, Properties and Multifunctional Application, International Journal of Nanoscience, 13, (2) 1430001, 1-22.

17-Laura, T., Manuel, A., Marcelo, K., Ana, R., Maritza, P. (2016) Copper-polymer nanocomposites: An excellent and cost-effective biocide for use on antibacterial surfaces, Materials Science and Engineering C, 69, 1391-1409.

18-Liming, D., Hans, J. G., Albert, W. H. M. (1997) Surface Modification by Plasma Etching and Plasma Patterning, J. Phys. Chem. B, 101 (46), 9548-9554.

19-Dorranian, D., Abedini, Z., Hojabri, A., Ghoranneviss, M. (2009) Structural and Optical characterization of PMMA surface treated in low power nitrogen and oxygen RF plasmas, Journal of Non-Oxide Glasses, 1 (3) 217 - 229.

20-Jacobs, T., Morent, R., De Geyter, N., Dubruel, P., Leys, C. (2012) Plasma surface modification of biomedical polymers: influence on cell-material interaction, Plasma chemistry and plasma processing, 32(5), 1039-1073.

21- Kumar, N.N., Seong, L.Y., Dayana, F. N., Khan, M.Z., Rama, P.S. (2016) Effect of Argon Plasma Treatment on Tribological Properties of UHMWPE/MWCNT Nanocomposites, Polymers, 8, 295-310,

22-Liston, E.M., Martinu, L., Wertheimer, M.R. (2012) Plasma surface modification of polymers for improved adhesion: a critical review, Journal of Adhesion Science and Technology, 7 , 1091-1127.

23-Kitova, S., Minchev M., Danev, G. (2005) Soft plasma treatment of polymer surfaces ,Journal of Optoelectronics and Advanced Materials, 7, 249 252.

24-Darain, F., Abdul Wahab, M., Tjin, S.C. (2012) Surface activation of poly(methel methacrylate) by plasma tratment: stable antibody immobilization for micro fluidic enzyme-linked immunosorbent assay, Analytical Letters, 45, 2569-2579.

25-Sánchez, B.L., Avila-Orta, C.A., Neira-Velazquez, M.G., Morones, P.G. Rodriguez-Gonzalez, J. A., Hernández, E., Rangel-Serrano, A., Castro, E.D., Yate, L., Ziolo, R.F. (2014) Enhanced Antibacterial Activity of Melt Processed Poly(propylene) Ag and $\mathrm{Cu}$ Nanocomposites by Argon Plasma Treatment, Plasma Processes and Polymers, 11 (4), 353-365.

26-Farag, O.F. (2019) A Comparative study of surface modification of PS films using Dc glow discharge plasma in $\mathrm{N}_{2}$ and Ar, Arab Journal of Nuclear Science and Applications, 52, 234-242.

27-Naglaa, M. E., Magdy, M. M., Omar, F. F.,Mohammed, H. E.(2012) $\mathrm{N}_{2}, \mathrm{~N}_{2}$-Ar and $\mathrm{N}_{2}-\mathrm{He}$
DC Plasmas for the improvement of Polymethylmethacrylate surface wettability, Adv. Appl. Sci. Res., 3(3), 1327-1334.

28-Jayakumar, N., Mohanamurugan, S., Rajavel, R., Srinivasan, V. (2015) Morphological characterization of poly methyl methacrylate for surface coating of metals, International Journal of Mechanical Engineering and Technology, 6 (8), 139-143.

29-Flávio, J.T., Leonardo, C. F., Lucas, G.P., Vínícius, O.A., Marcelo, H. P., Luiz, F. M., Maria, F.V. (2018) Poly (Methyl Methacrylate)-SiC Nanocomposites Prepared Through in Situ Polymerization, Materials Research, 21(6), 1-7.

30-Alexey, K. Marcela, B. (2011) Etching and structure changes in PMMA coating under argon plasma immersion ion implantation, Nuclear Instrum. Methods Phys. Res. B,269 (12) 1361-1369.

31-Vijayakumaria, G., Selvakumara , N., Jeyasubramaniana, K., Malab, R. ( 2013 ) Investigation on the Electrical Properties of Polymer metal Nanocomposites for Physiological sensing applications, Physics Procedia, 49, $67-78$.

32-Xiaokun, M., Xiaodan, S., Bing, Z., Zhao, X., Yumei, T., Zichen, W. (2011) Synthesis and Friction Properties of Copper/PMMA Composites by Soapless Emulsion Polymerization, Journal of Applied Polymer Science, 122, 2837-2842.

33-Chien-Chieh, H., Chen-Yuan, T., Yi-Chieh, W., ChiLan, L., Kueir-Rarn, L., Juin-Yih L. (2004) Effects of Plasma Treatment on $\mathrm{CO} 2$ Plasticization of Poly(methyl methacrylate) Gas-Separation Membranes, Journal of Applied Polymer Science, 93, $395-401$.

34-Andri, K.R., Debasish,M., Gary, H. F., Melina, S., Liedberg, B., Subbu, S.V., Jodhbir. S.M. (2015) Surface Modification of PMMA to Improve Adhesion to Corneal Substitutes in a Synthetic Core-Skirt Keratoprosthesis, ACS Appl. Mater. Interfaces, 7, 21690-21702.

35-Pawde, S.M., Kalim, D. (2009) Surface Characterization of Air Plasma Treated Poly Vinylidene Fluoride and Poly Methyl Methacrylate Films, Polymer engineering and science, 49 (4), 808818.

36-Kuvaldina, E.V., Rybkin, V.V., Titov, V.A., Shikova, T.G., Shutov, D.A. (2004) Oxidation and Degradation of Polypropylene in an Oxygen Plasma, High Energy Chemistry, 38 (6), 411-414.

37-Tomislava, V., Alenka, V., Matej, H., Mario, Š., Anet, R.J., Miran, M. (2018) Modification of Physico-Chemical Properties of Acryl-Coated Polypropylene Foils for Food Packaging by Reactive Particles from Oxygen Plasma, Materials, 11 (372), $1-17$.

38-Lim, H, Lee, Y., Han, S., Jeonghee, C., Kang-Jin, K. (2001). Surface treatment and characterization of PMMA, PHEMA, and PHPMA. J. Vac. Sci. Technol. A. 19 (4), 1490-1496. 
39-Lei, J., Songyan, L., Jiqian, W., Limin, Y., Qian, S., Zhaomin, L. (2014) Surface Wettability of Oxygen Plasma Treated Porous Silicon, Journal of Nanomaterials 2014, 1-6.

40-Gonzalez, E., Barankin, M.D., Gusch, P.C., Hicks, R.F. (2008) Remote atmospheric-pressure plasma activation of the surfaces of polyethylene terephthalate and polyethylene naphthalate, Langmuir, 24 (21), 12636-12643.

41-Eleazar, G., Michael, D.B., Peter, C.G., Robert, F.H. (2010) Surface Activation of Poly(methyl methacrylate) via Remote Atmospheric Pressure Plasma, Plasma Process. Polym., 7, 482-493.

42-Mortazavi, S.H., Ghoranneviss, M., Faryadras, S. (2011) Effect of low pressure nitrogen DC plasma on optical properties of biaxial- oriented polypropylene (BOPP), polymetylmethacrylate (PMMA) and polyvinyl chloride (PVC) films, J. Fusion Energy, 31, 211-215.

43- Singh, S, Prasher S. (2005) The optical, chemical and spectral response of gamma-irradiated Lexan polymeric track recorder. RadiatMeas, 40 (1), 50-54.

44- Kalsi, P.C., Agarwal, C. (2010) UV-irradiation effects on polyester nuclear track detector. Radiat Phys Chem., 79, 844-847.

45-Tauc, J., Amorphous and Liquid Semiconductors, Plenum Press, New York, 1979.

46-Atta, A., Abdel-Galil, A. (2016) Improved surface properties of PTFE polymer films using broad ion source, Indian Journal of Pure \& Applied Physics, 54, 551-556.

47- Qureshi , A., Singh, D., Singh, N.L., Ataoglu, S., Gulluoglu, A. N., Tripathi, A., Avasthi, D.K. (2009) Effect of irradiation by $140 \mathrm{Mev} \mathrm{Ag} 11+$ ions on the optical and electrical properties of polypropylene/ $\mathrm{TiO} 2$ composite Nuclear Instruments and Methods in Physics Research, B 267 (20) 34563460.

48-Farag, O.F., El-Sayed, N.M., Eaied, N.A. (2018) Effects of Low Temperature Plasma Treatment on Surface Properties of PS-Cu Nanocomposite Films Arab Journal of Nuclear Sciences and Applications, 51 (1) 194-203.

49-Rashidian, M., Dorranian, D. (2014) Low-intensity UV effects on optical properties of PMMA film, J Theor. Appl. Phys., 8 (121), 1-7. 